Como citar: Benvegnú, S. C., Detoni, P. P. \& Saldanha, O. M. F. L. (2022). Estudos da psicologia em situações de alienação parental: uma revisão sistemática. PSI UNISC, 6(1), 125-140. doi: 10.17058/psiunisc.v6i1.14831

\title{
Estudos da psicologia em situações de alienação parental: uma revisão sistemática
}

\author{
Estudios de psicología en situaciones de alienación: parental: una revisión sistemática
}

Studies of psychology in situations of parental alienation: a systematic review

Suany Chisté Benvegnú

Universidade do Vale do Taquari (Univates), Lajeado - RS/Brasil

ORCID: 0000-0003-3618-7447

E-mail: suanycb@ hotmail.com

Priscila Pavan Detoni

Universidade do Vale do Taquari (Univates), Lajeado - RS/Brasil

ORCID: 0000-0002-7436-2229

E-mail: ppavandetoni@gmail.com

\author{
Olinda Maria de Fátima Lechmann Saldanha \\ Universidade de Santa Cruz do Sul (UNISC), Santa Cruz do Sul - RS/Brasil \\ ORCID: 0000-0003-4189-4779 \\ E-mail: olindalsaldanha@gmail.com
}

\section{Resumo}

O presente artigo objetiva averiguar os estudos da Psicologia em situações de Alienação Parental (AP), analisando possibilidades de atenção/cuidado para com os sujeitos envolvidos nessas situações. A metodologia utilizada para o desenvolvimento do estudo foi uma revisão sistemática da literatura, baseada em estudos já elaborados. Para isso, utilizouse quatro bases de dados, sendo elas SCIELO, BVS, PEPSIC e DIALNET. Considerando-se que os estudos sobre a Alienação Parental e sobre as intervenções de profissionais da Psicologia são recentes, a análise foi baseada em publicações científicas, dos últimos seis anos, tendo em vista a data em que a Lei da Alienação Parental, $\mathrm{N}^{\circ}$ 12.318/10, foi decretada no Brasil. Os descritores utilizados para a pesquisa foram alienação parental, síndrome de alienação parental e divórcio. Os resultados apontam para a necessidade de uma maior especialização por parte de profissionais da Psicologia para lidar com situações que envolvem o Direito de Família, bem como evitar a judicialização das vidas e psicopatologização das relações de parentalidade. Além disso, deve-se buscar alternativas para que as intervenções de profissionais da Psicologia em situações de AP não estejam baseadas apenas nas perícias judiciais, mas nas diversas áreas de atuação da Psicologia.
\end{abstract}

Palavras-chaves: Psicologia; Pais; Família; Divórcio.

\section{Resumen}

El presente artículo tiene como objetivo averiguar esdtudios de Psicología en situaciones de Alienación Parental (AP), así analizando nuevas posibilidades de intervención/cuidado para con los sujetos involucrados en estas situaciones. La metodología utilizada para el desarrollo del estudio fue una revisión sistemática, basado en estudios ya elaborados. Con este fin, se utilizó cuatro bases de datos, que son SCIELO, BVS, PEPSIC e DIALNET. Teniendo en cuenta el hecho de que los estudios sobre la alienación parental y sobre intervenciones de la psicología profesional son recientes, el análisis se basó en publicaciones científicas, de los últimos siete años, en virtud de la fecha en que la Ley de la Alienación Parental, número 12.318 / 10, fue decretada en Brasil. Los descriptores utilizados para la investigación fueron alienación parental, síndrome de alienación parental y divorcio. Los resultados apuntan a la necesidad de una mayor especialización por parte de profesionales de la Psicología para hacer frente con situaciones que involucran el Derecho de Familia. Además, se deben buscar alternativas para que las intervenciones de profesionales de la Psicología en situaciones de AP no estén basadas apenas en la comprobación o no de su existencia, pero sí, en la búsqueda del cuidado integral de todos los sujetos involucrados, así como en la promoción de cuidado. 
Palabras clave: Psicologia; Padres; Família; Divorcio.

\begin{abstract}
This article aims to investigate studies f Psychology in situations of Parental Alienation (PA), analyzing possibilities of intervention/care for the subjects involved in these situations. The methodology used for the development of the study was a systematic review of the literature based on studies already elaborated. For this, four databases were used: SCIELO, BVS, PEPSIC and DIALNET. Considering the fact that the studies on Parental Alienation and the interventions of psychology professionals are recent, the analysis was based on
\end{abstract}

\section{Introdução}

A Alienação Parental (AP), pode ser considerada uma temática relativamente recente, que teve sua lei aprovada no Brasil no ano de 2010 (Lei 12.318, 2010). Segundo Velly (2010), a AP consiste em uma campanha de desmoralização que um dos cônjuges promove contra o outro, no qual a criança é utilizada como objeto de vingança, o que geralmente acaba repercutindo em uma violência psicológica. Além do termo AP, muitos autores ainda falam sobre a Síndrome de Alienação Parental (SAP), termo esse que foi definido pelo psiquiatra norte-americano, Richard Gardner (2002), como sendo um distúrbio infantil que atingiria principalmente crianças que estão envolvidas em situação de disputa de guarda entre os pais. Essa "síndrome" estaria relacionada aos problemas comportamentais e emocionais que surgem como consequência do processo de AP explicado anteriormente. Apesar destas referências, a SAP não consta nos manuais diagnósticos como o CID X, DSM $\mathrm{V}$, o que a faz necessária de problematizações e estudos.

Ao longo deste estudo, buscamos contextualizar as relações familiares, em que perpassam questões como a conjugalidade, parentalidade e rompimento de laços matrimoniais. Em seguida, iniciamos uma discussão voltada para a violência psicológica contra crianças e adolescentes, dando ênfase à contextualização da AP e diferenciação da SAP, a partir da análise da revisão sistemática. $O$ presente artigo objetiva averiguar os estudos da scientific publications of the last six years, due to the date in which the Parental Alienation Law n ${ }^{\circ} 12.318$ / 10 was decreed in Brazil. The descriptors used for the research were parental alienation and parental, alienation syndrome and divorce. The results indicate the need for greater specialization on the part of Psychology professionals to deal with situations that involve Family Law. Besides that, it's necessary to seek alternatives so that the interventions of professionals of Psychology in PA situations don't be based only in judicial investigations, but in the various areas of Psychology.

Keywords: Psychology; Parents; Family; Divorce.

Psicologia em situações de Alienação Parental (AP), analisando possibilidades de atenção/cuidado para com os sujeitos envolvidos nessas situações.

Por fim, apresentaremos os resultados da pesquisa, explicitando elementos que nos auxiliem a (re)pensar as intervenções que estão sendo realizadas por profissionais da Psicologia em situações de AP nos últimos anos, analisando assim novas possibilidades de cuidado para com os sujeitos envolvidos nessas situações. A relevância deste estudo está na oportunidade de ampliarmos o campo de intervenção dos/as psicólogos/as, visando o cuidado às famílias que vivenciam processos de dissolução conjugal ou disputas de guarda. Além disso, contribuir para a ampliação e articulação de conhecimentos do campo da Psicologia e do Direito, proporcionando melhor qualificação das ações de prevenção das situações de sofrimento e cuidado.

\section{Família e dissolução conjugal}

O contexto familiar passou por muitas mudanças ao longo do tempo. Antigamente, além de ser responsável pela administração das finanças e bens familiares, o homem era detentor de todo o poder, tendo autoridade para tomar as decisões necessárias em relação a casa, esposa e filhos (Neder \& Filho, 2007). Com o passar dos anos a mulher, que era tratada com inferioridade, passa a conquistar cada vez mais seu espaço, sendo reconhecida juridicamente a igualdade. Um longo trajeto foi percorrido para que o exercício do poder 
familiar passasse a ser dividido entre homens e mulheres, principalmente no momento em que se torna igualitário os direitos e deveres relacionados à vida familiar, como a conjugalidade e a parentalidade (Guilhermano, 2012).

Para Coelho (2017), a conjugalidade pode ser entendida como um vínculo construído por dois indivíduos que passam a estabelecer um outro elemento, a relação do casal. Cada um de nós possui uma individualidade que é construída através de nossas histórias, sonhos, desejos e vivências, mas, como aponta Féres-Carneiro (2008), é necessário que possamos nos adaptar com as diferenças e respeitar a identidade de cada sujeito para que seja possível construir uma relação de forma conjunta. Apesar de, para muitas pessoas, a conjugalidade ainda vir acompanhada de promessas de amor e felicidade eterna, com a expectativa da formação de uma família com base no respeito, diálogo e cumplicidade, as relações implicam em conflitos, o que pode resultar em situações de separação e divórcio (Campos, 2002).

Apesar de não ser uma regra, a AP geralmente ocorre a partir de uma situação de dissolução conjugal que, segundo Campos (2002), consiste em uma ruptura dos laços matrimoniais existentes entre um casal, podendo ser pela rescisão de um contrato civil, quando são oficialmente casados, ou de um contrato de fato, união estável, regulamentada por lei. Ainda para o autor, não podemos pensar no divórcio apenas como algo que será desfeito no papel, já essa ruptura irá suscitar inúmeros sentimentos e mudanças. Sendo assim, para Bee e Boyd (2011), o divórcio não é uma variável unilateral já que, se crianças estiverem envolvidas na situação, vão ser afetadas de alguma forma, podendo ser por conflitos parentais, distanciamento de um dos genitores, ou até mudanças na rotina diária.

Para muitos casais que optam pelo divórcio, a maior dificuldade passa a ser a forma como vão agir em relação aos filhos, já que há um rompimento do laço da conjugalidade, mas não da parentalidade (Melo
\& Miccione, 2014). Para algumas crianças, o divórcio dos pais é considerado algo extremamente difícil e que vem acompanhado de um grande medo do abandono. Ao ver um dos pais saindo de casa, a criança pode ter a sensação de que o vínculo ali presente será totalmente rompido e que ela será esquecida. Para outras, a separação surge como um alívio, uma libertação para todos os conflitos que ocorriam em casa (Melo \& Miccione, 2014). Segundo Papalia, Olds e Feldman (2006), cada criança lida com as situações de separação de forma diferente, sendo assim, é preciso analisar em que circunstâncias ela ocorreu, já que conflitos matrimoniais podem ser extremamente mais prejudiciais para a criança do que a situação do divórcio.

Após uma situação de divórcio, muitas dúvidas surgem em relação aos papéis que foram constituídos até então e como serão os relacionamentosa partir daquele momento. Segundo Pasqua (2017), a parentalidade é um conjunto de funções e atividades que são realizadas pelos pais ou responsáveis, tendo por principal objetivo propiciar o desenvolvimento da criança de forma saudável, movimentos que são feitos desde o período de gestação. Um ponto importante a ser ressaltado é que a parentalidade não se encerra quando há uma situação de separação do casal, muito pelo contrário, os pais continuam tendo a obrigação de assegurar o cuidado com a prole, procurando não (re)produzir violências decorrentes deste período de mudança e de ressentimentos (Kell, 2004).

A violência é considerada um problema social e de saúde pública que acaba por vitimar inúmeras crianças e adolescentes no Brasil e no mundo (Fermann \& Pelisoli, 2016). Ela pode ocorrer de diversas formas, como por exemplo, a violência física, verbal, moral, psicológica, da qual nos debruçaremos a seguir. De Antoni (2012), a violência psicológica é uma das que mais atinge crianças e adolescentes, podendo manifestar-se através de rejeição, discriminação, humilhação, cobranças exageradas em relação à criança, negação de afeto, ameaças, entre outros. Segundo a Organização Mundial da Saúde (OMS), a 
violência é definida como uso da força real ou ameaça, contra outra pessoa, contra si próprio, grupo ou comunidade. Ela deve resultar ou ter qualquer possibilidade de resultar uma lesão, morte, dano psicológico, entre outros (OMS, 2002).

Para Fermann e Pelisoli (2016) uma das formas de violência psicológica contra crianças e adolescentes que ocorre no contexto familiar é a AP que, conforme o Artigo $2^{\circ}$ da Lei $n^{\circ}$ 12.318/10, consiste na interferência na formação psicológica da criança/adolescente, sendo provocada por um dos genitores, familiares próximos ou responsável legal, que tem como objetivo fazer com que estes passem a repudiar seu outro genitor/cuidador. Ainda conforme a lei, tais atitudes seriam consideradas como abuso moral, pois teriam ferido os direitos à convivência saudável da família e prejudicam a integridade psicológica da criança/adolescente (Oliveira \& Brito, 2012).

Abranches e Assis (2011), nos dizem que os estudos referentes especificamente à violência psicológica, bem como AP, ainda são escassos. Um dos principais motivos identificados seria o fato de que essa violência não deixa marcas físicas, mas sim psicológicas, o que torna mais complexo o processo de identificação.

\section{Alienação Parental e Síndrome de Alienação Parental}

Como mencionado anteriormente, segundo Velly (2010), a AP consiste em uma campanha de desmoralização que um dos cônjuges promove contra o outro, no qual a criança é utilizada como objeto de vingança. É também considerada uma manipulação realizada por um dos pais, tendo como principal objetivo fazer com que o(a) filho(a) volte-se contra o outro, "programando" a criança para sentir raiva, ódio entre outros sentimentos (Simão, 2008). Para Morais (2012), a AP não é apenas identificada quando há uma situação de divórcio, pelo contrário, pode estar presente em situações que ocorrem anteriormente a isso, também podendo envolver outros parentes próximos.

O termo SAP foi definido pelo psiquiatra Richard Gardner (2002), como um distúrbio infantil que atingiria principalmente crianças que estão envolvidas em situação de disputa de guarda entre os pais. Ela está relacionada aos problemas comportamentais e emocionais que surgem como consequência do processo de AP explicado anteriormente. Os estudos de Gardner apontam alguns dos sintomas que podem ser observados em crianças que estão sofrendo com a SAP:

Uma campanha denegritória contra o genitor alienado; racionalizações fracas, absurdas ou frívolas para a depreciação; falta de ambivalência; o fenômeno do "pensador independente"; apoio automático ao genitor alienador no conflito parental; ausência de culpa sobre a crueldade a e/ou a exploração contra o genitor alienado; a presença de encenações "encomendadas"; propagação da animosidade aos amigos e/ou à família extensa do genitor alienado (2002, p. $3)$.

Ainda segundo Gardner (2002), a SAP poderia ser identificada em três níveis, sendo eles: leve, moderado e severo. No nível leve, os sintomas não aparecem de forma intensa. No moderado (mais comum), os sintomas acabam sendo mais evidentes, podendo ser percebidos por comentários que a criança faz depreciando um dos pais, vendo este como mau e o outro como bom. Além disso, há relutância em fazer visitas para o genitor não detentor de sua guarda, mas podem, quando o alienador não está por perto, permitir uma maior aproximação. $\mathrm{O}$ terceiro e menos frequente nível é o severo. Neste os sintomas tornam-se muito mais evidentes, de modo que a criança e o alienante compartilham fantasias paranoides em relação ao outro, fazendo com que uma simples visita se torne algo impossível. Apesar destas referências, a SAP não consta nos manuais diagnósticos, o que demanda problematizações em relação ao uso desse 
termo, o que alguns estudos o referem utilizar somente o termo Alienação Parental.

\section{Metodologia}

Trata-se de um estudo qualitativo desenvolvido por meio da revisão sistemática da literatura, que consiste em um estudo secundário, tendo como sua principal fonte de dados estudos primários, como por exemplo, artigos científicos (Galvão \& Pereira, 2014). A revisão sistemática busca responder determinada pergunta da pesquisa, exigindo uma rigorosa revisão. Este difere do método de revisão bibliográfica por responder a uma pergunta mais pontual (Guanilo, Takahashi, \& Bertolozzi, 2011).

Neste estudo a principal questão foi averiguar os estudos da Psicologia em situações de Alienação Parental (AP), analisando possibilidades de atenção/cuidado para com os sujeitos envolvidos nessas situações pós surgimento da Lei $\mathrm{N}^{\circ} 12.318 / 10$ (Lei n. 12.318, 2010). Portanto, a análise foi baseada em publicações científicas, posterior a $2010 \mathrm{em}$ virtude da data em que a Lei da Alienação Parental foi decretada no Brasil.

Para isso, utilizou-se quatro bases de dados, sendo elas SCIELO, BVS, PEPSIC e DIALNET. Os descritores empregados para a pesquisa foram alienação parental, síndrome de alienação parental e divórcio. $\mathrm{Na}$ etapa seguinte, foram definidos os critérios de inclusão dos materiais, sendo: artigos empíricos e teóricos relacionados ao tema, período de publicação dos materiais entre os anos de 2010 até 2017, totalizando um período de 7 anos e idioma em português. Destaca-se que foram excluídos os artigos em duplicidade, fora do período de tempo proposto, dissertações e teses. A etapa seguinte se caracterizou pela análise criteriosa dos materiais, sendo que para isso, foi construído um instrumento de registro contendo as seguintes informações: ano da publicação e autores, título do artigo, periódico de publicação e base de dados, objetivos, métodos, resultados e conclusões. Nota-se que este instrumento auxiliou na compilação dos principais elementos de cada estudo, bem como para análise.

\section{Resultados}

Elaboramos uma tabela com base nos 27 artigos encontrados, 13 artigos selecionados a partir dos descritores utilizados, leitura dos resumos e do artigo completo. Ela foi organizada a partir do título de cada artigo, bem como local de produção e base de dados, objetivos, intervenções de profissionais da Psicologia, metodologia de pesquisa e a abordagem do tema a partir da utilização do termo AP e/ou SAP.

Todas as pesquisas analisadas foram sobre pesquisas qualitativas, oito delas são revisões bibliográficas, duas de cunho exploratório, sendo que uma utilizou a observação, análise de documentos e entrevistas semiestruturadas em um projeto de Mediação de Conflitos, em uma faculdade no interior do Rio Grande do Sul (RS) e a outra aplicou questionários com profissionais de Psicologia do judiciário do RS. Outro estudo foi realizado a partir de entrevistas semiestruturadas com uma equipe da Vara de Família do Fórum Lafayette, de Minas Gerais (MG). Outro estudo realizou análise documental descritiva a partir de laudos psicológicos, e por fim, outro estudo foi realizado a partir de uma revisão integrativa, analisando publicações sobre AP. 
Tabela 1

Apresentação dos resultados

\begin{tabular}{|c|c|c|c|c|c|}
\hline Artigo & $\begin{array}{c}\text { Local da } \\
\text { Produção } \\
\text { e Base de } \\
\text { Dados }\end{array}$ & Objetivos & $\begin{array}{l}\text { Intervenções } \\
\text { Psicológicas }\end{array}$ & $\begin{array}{l}\text { Metodologia } \\
\text { de Pesquisa }\end{array}$ & $\begin{array}{c}\text { Aborda AP } \\
\text { ou SAP }\end{array}$ \\
\hline $\begin{array}{c}\text { Síndrome de } \\
\text { alienação parental, } \\
\text { falso abuso sexual e } \\
\text { guarda } \\
\text { compartilhada: a } \\
\text { necessidade de uma } \\
\text { observação jurídica } \\
\text { transdisciplinar } \\
\text { Souza e Barreto, } \\
2011\end{array}$ & $\begin{array}{l}\text { Joaçaba - } \\
\text { SC } \\
\text { DIALNET }\end{array}$ & $\begin{array}{l}\text { Relacionar a SAP, o } \\
\text { falso abuso sexual e a } \\
\text { guarda compartilhada } \\
\text { partindo de uma } \\
\text { perspectiva } \\
\text { transdisciplinar. }\end{array}$ & $\begin{array}{l}\text { Aborda o trabalho } \\
\text { dos operadores do } \\
\text { Direito e da } \\
\text { Psicologia, } \\
\text { destacando a } \\
\text { importância da } \\
\text { transdisciplinaridade. }\end{array}$ & $\begin{array}{c}\text { Qualitativa: } \\
\text { Revisão } \\
\text { Bibliográfica a } \\
\text { partir da } \\
\text { análise da Lei } \\
\mathrm{n}^{\circ} 12.318 / 10 .\end{array}$ & $\begin{array}{l}\text { A SAP seria } \\
\text { consequência } \\
\text { da AP. }\end{array}$ \\
\hline $\begin{array}{c}\text { Síndrome de } \\
\text { Alienação Parental: } \\
\text { da teoria norte- } \\
\text { americana à nova lei } \\
\text { brasileira } \\
\text { Sousa e Brito, } \\
2011\end{array}$ & $\begin{array}{c}\text { Rio de } \\
\text { Janeiro - } \\
\text { RJ } \\
\text { SCIELO }\end{array}$ & $\begin{array}{c}\text { Examinar argumentos } \\
\text { que fundamentaram a } \\
\text { exposição de motivos } \\
\text { do projeto de lei sobre } \\
\text { a AP, explanando-se } \\
\text { também as decisões } \\
\text { judiciais proferidas em } \\
\text { diferentes países que } \\
\text { tomaram por base esse } \\
\text { conceito. }\end{array}$ & $\begin{array}{c}\text { Realização de } \\
\text { perícias psicológicas } \\
\text { e escrita de laudos. } \\
\text { Trabalho do } \\
\text { Psicólogo confundido } \\
\text { com de advogados ou } \\
\text { investigadores. }\end{array}$ & $\begin{array}{l}\text { Qualitativa: } \\
\text { Revisão } \\
\text { bibliográfica a } \\
\text { partir da } \\
\text { análise do } \\
\text { Projeto de Lei } \\
\text { da Alienação } \\
\text { Parental e } \\
\text { aplicação no } \\
\text { contexto } \\
\text { brasileiro. } \\
\end{array}$ & $\begin{array}{c}\text { Problematiza } \\
\text { AP e SAP. }\end{array}$ \\
\hline $\begin{array}{c}\text { Reflexões sobre } \\
\text { alienação parental } \\
\text { em um projeto de } \\
\text { mediação de } \\
\text { conflitos } \\
\text { Luz, Gelain e Lima, } \\
2014\end{array}$ & $\begin{array}{l}\text { Campo } \\
\text { Grande - } \\
\text { MS } \\
\text { PEPSIC }\end{array}$ & $\begin{array}{c}\text { Refletir sobre a } \\
\text { importância da } \\
\text { mediação de conflitos } \\
\text { na amenização e/ou } \\
\text { eliminação da AP nos } \\
\text { casos atendidos no } \\
\text { projeto Mediação de } \\
\text { Conflitos da faculdade } \\
\text { IMED de Passo Fundo. }\end{array}$ & $\begin{array}{c}\text { Participação de } \\
\text { psicólogos durante as } \\
\text { mediações }\end{array}$ & $\begin{array}{c}\text { Pesquisa } \\
\text { qualitativa de } \\
\text { cunho } \\
\text { exploratório, } \\
\text { utilizando } \\
\text { observação, } \\
\text { análise de } \\
\text { documentos e } \\
\text { entrevistas } \\
\text { semi- } \\
\text { estruturadas } \\
\end{array}$ & $\begin{array}{l}\text { Utiliza AP e } \\
\text { SAP de forma } \\
\text { indiscriminad } \\
\text { a }\end{array}$ \\
\hline $\begin{array}{c}\text { A atuação do } \\
\text { Psicólogo Jurídico } \\
\text { na alienação } \\
\text { parental }\end{array}$ & $\begin{array}{l}\text { Passo } \\
\text { Fundo - } \\
\quad \text { RS }\end{array}$ & $\begin{array}{l}\text { Refletir sobre a } \\
\text { importância do } \\
\text { Psicólogo Jurídico no } \\
\text { Direito de Família e } \\
\text { principalmente em } \\
\text { questões de AP. }\end{array}$ & $\begin{array}{c}\text { Psicólogo Jurídico: } \\
\text { fazer estudo social; } \\
\text { Relatar situações } \\
\text { identificadas para o } \\
\text { juiz; } \\
\text { Atendimento } \\
\text { psicológico para } \\
\text { todos os envolvidos }\end{array}$ & $\begin{array}{l}\text { Qualitativa de } \\
\text { cunho } \\
\text { exploratório. } \\
\text { Pesquisa } \\
\text { Empírica com } \\
\text { aplicação de } \\
\text { Questionários } \\
\text { com } \\
\text { Profissionais } \\
\text { de Psicologia } \\
\text { do Judiciário } \\
\text { do RS. }\end{array}$ & $\begin{array}{c}\text { Utiliza AP e } \\
\text { SAP de forma } \\
\text { indiscriminad } \\
\text { a }\end{array}$ \\
\hline $\begin{array}{c}\text { A consagração das } \\
\text { vítimas nas } \\
\text { sociedades de } \\
\text { segurança }\end{array}$ & $\begin{array}{c}\text { Rio de } \\
\text { Janeiro - } \\
\text { RJ } \\
\text { PEPSIC }\end{array}$ & $\begin{array}{l}\text { Contribuir com os } \\
\text { debates acerca da } \\
\text { consagração das } \\
\text { vítimas em sua } \\
\text { articulação com o } \\
\text { incremento das } \\
\text { sociedades de } \\
\text { segurança. }\end{array}$ & $\begin{array}{l}\text { Proteção e reparação } \\
\text { às vítimas; } \\
\text { Profissionais da } \\
\text { psicologia acabam } \\
\text { tendo que dizer se há } \\
\text { sofrimento, doença, } \\
\text { danos psíquicos que } \\
\text { foram causados. }\end{array}$ & $\begin{array}{l}\text { Qualitativa: } \\
\text { Revisão } \\
\text { Bibliográfica }\end{array}$ & $\begin{array}{l}\text { Utiliza AP ao } \\
\text { longo da } \\
\text { escrita. }\end{array}$ \\
\hline
\end{tabular}


Fala sobre o desejo

de punir os culpados

e consagrar as vítimas

\begin{tabular}{|c|c|c|c|c|c|}
\hline $\begin{array}{c}\text { Contribuições da } \\
\text { Teoria Sistêmica } \\
\text { acerca } \\
\text { da Alienação } \\
\text { Parental } \\
\text { Coelho e Morais, } \\
2014\end{array}$ & $\begin{array}{c}\text { Fortaleza - } \\
\text { CE } \\
\text { SCIELO }\end{array}$ & $\begin{array}{l}\text { Descrever algumas } \\
\text { contribuições da teoria } \\
\text { sistêmica que podem } \\
\text { ajudar a compreender o } \\
\text { fenômeno da AP. }\end{array}$ & $\begin{array}{l}\text { Compreensão dos } \\
\text { inúmeros aspectos da } \\
\text { dinâmica familiar } \\
\text { para obter formas de } \\
\text { intervenção mais } \\
\text { adequadas. }\end{array}$ & $\begin{array}{l}\text { Qualitativa: } \\
\text { Revisão } \\
\text { Bibliográfica. }\end{array}$ & $\begin{array}{l}\text { Intitula SAP } \\
\text { como sendo } \\
\text { uma } \\
\text { consequência } \\
\text { da AP. }\end{array}$ \\
\hline $\begin{array}{c}\text { Alienação Parental: } \\
\text { Complexidades } \\
\text { Despertadas no } \\
\text { Âmbito Familiar } \\
\text { Nuske e } \\
\text { Grigorieff, } \\
2015 \\
\end{array}$ & $\begin{array}{c}\text { Porto } \\
\text { Alegre - } \\
\text { RS } \\
\text { SCIELO }\end{array}$ & $\begin{array}{l}\text { Evidenciar o cenário no } \\
\text { qual no qual a } \\
\text { alienação parental } \\
\text { ocorre e as } \\
\text { consequências que este } \\
\text { fenômeno implica. }\end{array}$ & $\begin{array}{l}\text { Tratamento } \\
\text { psicológico. }\end{array}$ & $\begin{array}{l}\text { Qualitativa: } \\
\text { Revisão } \\
\text { Bibliográfica. }\end{array}$ & $\begin{array}{c}\text { Utiliza apenas } \\
\text { AP ao longo } \\
\text { da escrita. }\end{array}$ \\
\hline $\begin{array}{l}\text { Alienação parental e } \\
\text { relações escolares: a } \\
\text { atuação do } \\
\text { Psicólogo } \\
\\
\text { Jesus e Cotta, } \\
2016\end{array}$ & $\begin{array}{l}\text { Belo } \\
\text { Horizonte } \\
-\mathrm{MG} \\
\text { SCIELO }\end{array}$ & $\begin{array}{l}\text { Pensar em possíveis } \\
\text { intervenções do } \\
\text { Psicólogo escolar em } \\
\text { situações de AP que } \\
\text { provocam dificuldades } \\
\text { no processo de } \\
\text { escolarização. }\end{array}$ & $\begin{array}{l}\text { Psicólogo Escolar: } \\
\text { propiciar um } \\
\text { ambiente em que as } \\
\text { relações sejam } \\
\text { baseadas no respeito } \\
\text { mútuo e formação de } \\
\text { vínculos. } \\
\text { Pensar em estratégias } \\
\text { juntamente com } \\
\text { outros membros da } \\
\text { escola, trabalho } \\
\text { multidisciplinar. }\end{array}$ & $\begin{array}{l}\text { Qualitativa: } \\
\text { Revisão } \\
\text { Bibliográfica }\end{array}$ & $\begin{array}{l}\text { Intitula SAP } \\
\text { como sendo } \\
\text { uma } \\
\text { consequência } \\
\text { da AP. }\end{array}$ \\
\hline $\begin{array}{c}\text { A Psicoterapia } \\
\text { Cognitivo- } \\
\text { Comportamental } \\
\text { para Crianças e } \\
\text { Adolescentes } \\
\text { vítimas de Violência } \\
\text { Psicológica e } \\
\text { Alienação Parental } \\
\text { Fermann e Pelisoli, } \\
2016\end{array}$ & $\begin{array}{c}\text { Passo } \\
\text { Fundo- RS } \\
\text { DIALNET }\end{array}$ & $\begin{array}{c}\text { Caracterizar e discutir a } \\
\text { violência psicológica } \\
\text { sofrida por crianças e } \\
\text { adolescentes e as } \\
\text { consequências desta } \\
\text { para o } \\
\text { desenvolvimento. } \\
\text { Verificar como a } \\
\text { psicoterapia Cognitivo } \\
\text {-Comportamental está } \\
\text { sendo utilizada para o } \\
\text { tratamento desses } \\
\text { casos. }\end{array}$ & $\begin{array}{c}\text { Utilização da } \\
\text { Psicoterapia } \\
\text { Cognitivo - } \\
\text { Comportamental para } \\
\text { crianças/adolescentes } \\
\text { vítimas de violência } \\
\text { psicológica e AP. }\end{array}$ & $\begin{array}{l}\text { Qualitativa: } \\
\text { Revisão } \\
\text { Bibliográfica }\end{array}$ & $\begin{array}{l}\text { Utiliza o } \\
\text { termo AP } \\
\text { explicando } \\
\text { que a SAP } \\
\text { ainda é } \\
\text { controversa } \\
\text { no meio } \\
\text { científico. }\end{array}$ \\
\hline
\end{tabular}

Publicações

Psicojurídicas sobre

AP: Uma revisão

integrativa da

literatura em português
Maringá -
PR
BVS

Mendes, Maluschke,

Vasconcelos,

Fernandes e Costa, 2016
Compreensão dos números aspectos da dinâmica familiar para obter formas de ervenção mais fenômeno da AP.
Descrever algumas

CE sistêmica que podem
Qualitativa:
Revisão

mo sendo

nsequência

da AP.
Evidenciar o cenário no qual no qual a enação parental nsequências que este fenômeno implica.
Tratamento
psicológico.

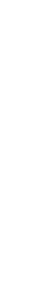

.

sicólogo Escolar:

biente em que as

relações sejam

baseadas no respeito vínculos.

ensar em estratégia

escola, trabalho

sciplinar.

\section{ação da \\ Psicoterapia}

omportamental para crianças/adolescentes vítimas de violência psicológica e AP. científica de periódicos envolvendo temática da AP.
Investigar a qualidade
A grande maioria dos artigos não foram escritos por profissionais da área da psicologia.
Qualitativa:

Revisão

integrativa, Problematiza analisando AP e SAP. publicações sobre AP. 


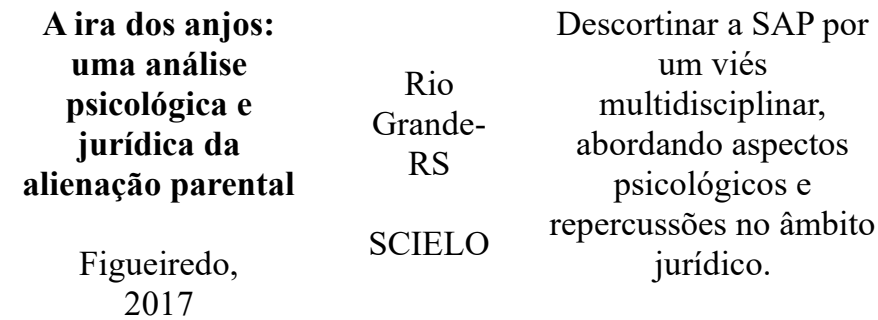

$\begin{array}{ccc} & \text { Qualitativa: } & \text { Intitula SAP } \\ \text { Acompanhamento } & \text { Revisão } & \text { como sendo } \\ \text { psicológico. } & \text { partiográfica a } & \text { uma } \\ \text { Perícias e laudos. } & \text { consequência } \\ & \begin{array}{c}\text { análise da Lei } \\ \mathrm{n}^{\circ} 12.318 / 10 .\end{array} & \text { da AP. }\end{array}$

Qualitativa: Intitula SAP

Bibliográfica a uma

análise da Lei da AP.

$\mathrm{n}^{\mathrm{o}} 12.318 / 10$.

\begin{tabular}{|c|c|c|c|c|c|}
\hline $\begin{array}{c}\text { Abordagens da } \\
\text { alienação parental: } \\
\text { proteção e/ou } \\
\text { violência? } \\
\text { Montezuma, Pereira e } \\
\text { Melo, } \\
2017\end{array}$ & $\begin{array}{l}\text { Rio de } \\
\text { Janeiro - } \\
\text { RJ } \\
\text { SCIELO }\end{array}$ & $\begin{array}{c}\text { Analisar as abordagens } \\
\text { da AP a partir das } \\
\text { dimensões conceitual, } \\
\text { de poder e operativa. }\end{array}$ & $\begin{array}{l}\text { Perícia psicológica ou } \\
\text { biopsicossocial, } \\
\text { havendo alguns } \\
\text { questionamentos } \\
\text { sobre a psicologia em } \\
\text { relação as perícias. }\end{array}$ & $\begin{array}{c}\text { Pesquisa } \\
\text { qualitativa } \\
\text { utilizando } \\
\text { entrevistas } \\
\text { semiestruturad } \\
\text { as com equipe } \\
\text { da Vara de } \\
\text { Família do } \\
\text { Fórum } \\
\text { Lafayette, de } \\
\text { BH. } \\
\end{array}$ & $\begin{array}{l}\text { Consideram } \\
\text { inadequado o } \\
\text { termo SAP. }\end{array}$ \\
\hline $\begin{array}{c}\text { Perícias Psicológicas } \\
\text { em Processos } \\
\text { Judiciais } \\
\text { Envolvendo } \\
\text { Suspeita de } \\
\text { Alienação Parental } \\
\text { Fermann, Chambart, } \\
\text { Foschiera, Bordini e } \\
\text { Habigzang, } \\
2017\end{array}$ & $\begin{array}{c}\text { Porto } \\
\text { Alegre - } \\
\text { RS } \\
\text { DIALNET }\end{array}$ & $\begin{array}{l}\text { Verificar os critérios e } \\
\text { indicadores de AP } \\
\text { considerados pelos } \\
\text { psicólogos em perícias } \\
\text { incluídas em processos } \\
\text { envolvendo guarda de } \\
\text { crianças e suspeita de } \\
\text { AP, investigar quais os } \\
\text { procedimentos de } \\
\text { avaliação adotados, } \\
\text { avaliar a adequação dos } \\
\text { laudos psicológicos } \\
\text { emitidos pelos } \\
\text { profissionais nomeados } \\
\text { pelos juízes tendo } \\
\text { como base orientação } \\
\text { do CFP, verificar se } \\
\text { houve concordância } \\
\text { entre conclusão do } \\
\text { laudo psicológico e da } \\
\text { sentença judicial sobre } \\
\text { presença/ausência de } \\
\text { AP. }\end{array}$ & $\begin{array}{c}\text { Psicólogo como } \\
\text { Perito e que realiza } \\
\text { Avaliação } \\
\text { Psicológica. } \\
\text { Analise de Laudos } \\
\text { Psicológicos, os quais } \\
\text { não estavam de } \\
\text { acordo com as } \\
\text { normas da Resolução } \\
\text { 07/2003 do Conselho } \\
\text { Federal de Psicologia. }\end{array}$ & $\begin{array}{l}\text { Quantitativa: } \\
\text { Analise } \\
\text { Documental } \\
\text { Descritiva a } \\
\text { partir de } \\
\text { laudos } \\
\text { psicológicos. }\end{array}$ & $\begin{array}{l}\text { Utiliza dos } \\
\text { dois termos } \\
\text { referindo que } \\
\text { a SAP ainda é } \\
\text { controversa e } \\
\text { inconsistente. }\end{array}$ \\
\hline
\end{tabular}

Nota. Tabela desenvolvida pelas autoras em 2018.

Em relação à utilização dos termos Alienção Parental e Síndrome da Alienação Parental (SAP), quatro artigos consideram a SAP como sendo uma consequência da AP, dois deles problematizam ambos os termos, e dois deles utilizam AP e SAP de forma indiscriminada, dois utilizam o termo AP explicando que a SAP ainda é controversa no meio científico, um considera inadequado o termo SAP. Entre os estudos, seis artigos abordam a realização de perícias e/ou estudos sociais e elaboração de laudos como sendo uma das possibilidades de intervenção de profissionais da Psicologia em situações de AP, sendo que quatro deles promovem questionamentos em relação a isso. Uma das pesquisas aborda a temática da mediação, quatro referem-se ao acompanhamento psicológico de crianças e adolescentes envolvidos em situações de AP e/ou seus genitores. A importância da transdisciplinaridade é destacada em um dos estudos e outro refere-se à equipe multidisciplinar e ao trabalho do/a psicólogo/a 
escolar. Apenas uma publicação discute em seu estudo o fato de que a grande maioria dos artigos analisados não foram escritos por profissionais da área da Psicologia. Outro estudo enfatiza a compreensão dos inúmeros aspectos da dinâmica familiar para obter formas de intervenção mais adequadas.

\section{Análise dos Resultados Utilização do termo AP e/ou SAP}

Um dos primeiros pontos a serem analisados neste estudo diz respeito às diferentes concepções que envolvem os termos AP e SAP. O psiquiatra Richard Gardner (2002) fundamentou que a intitulada SAP fosse considerada uma doença, porém, essa síndrome não está presente nos manuais diagnósticos de saúde mental - CID X e DSM. Contudo, nos artigos analisados há uma discussão/problematização em relação a AP ser considerada uma síndrome, estando entre eles os seguintes autores Sousa e Brito (2011), Coelho e Morais (2014), Fermann e Pelisoli (2016), Mendes, Maluschke, Vasconcelos, Fernandes e Costa (2016) e Montezuma, Pereira e Melo (2017). Ao longo de sua escrita, tais autores conceituam o que seria a SAP. Além de questionar a SAP, Sousa e Brito (2011) problematizam a AP, principalmente por considerarem que há um risco de que, em todas as situações de litígio, a AP e/ou SAP sejam naturalizadas e também, patologizadas.

Apesar das discussões que envolvem os conceitos de AP e SAP, muitos autores ainda consideram que a segunda seria uma consequência da primeira, conforme Souza e Barreto (2011) e Jesus e Cotta (2016) e Figueiredo (2017). Coelho e Morais (2014), também enfatizam a ausência da SAP nos manuais diagnósticos e a consideram uma consequência da AP.

A SAP necessita de maior problematização em virtude de sua não comprovação científica e incentivo a psicopatologização e judicialização da vida (Prado Filho, 2012). Segundo o autor, as práticas jurídicas têm produzido verdades sobre os sujeitos e suas formas de se relacionar articuladas com os saberes psicológicos. Algumas situações cotidianas pelas quais perpassamos ao longo de nossas vidas acabam sendo reduzidas a uma concepção individualizante através da judicialização, no sentido de contar com um terceiro (especialista) para intervir na reparação dos danos causados, ou nas relações a partir das normas sociais. O processo de judicialização consiste em um movimento de regulação normativa e legal do viver, em que os sujeitos se apropriam de leis e normas para a resolução de conflitos (Oliveira e Brito, 2012).

Segundo Fermann, Chambart, Foschiera, Bordini e Habigzang (2017), a dita síndrome ainda é considerada incongruente, principalmente pelo fato de haver uma dificuldade em identificar os "sintomas" que poderiam ser observados em crianças/adolescentes que seriam vítimas desta. Os equívocos relacionados a avaliação da SAP estariam presentes pelo fato de que os comportamentos identificados podem ser comuns para crianças/adolescentes quando se trata de uma situação que envolve o divórcio dos pais e reorganização do ambiente familiar.

Para Sousa (2014), situações e comportamentos, conforme os que foram citados anteriormente, que podem fazer parte da vida de cada sujeito em determinado momento de sua vida, passam a ser considerados algo patológico e anormal. A partir dessas concepções entendemos que nos casos de AP, cabe não somente a busca por um diagnóstico, mas pensar mais sobre a real responsabilidade profissional de produção de verdades sobre as vidas que intervém como psicólogo/a ou operador do Direito, em especial no Direito de Família, para evitar uma lógica de judicialização e produzir formas de cuidado.

\section{Intervenções de Profissionais da Psicologia}

As intervenções realizadas por profissionais da Psicologia têm grande importância em situações relacionadas ao Direito de Família, principalmente em casos que envolvem crianças e adolescentes, que estão em fase de desenvolvimento e precisam 
de cuidados. A partir dos 13 artigos analisados, podemos identificar diferentes formas de intervenção realizadas por profissionais da Psicologia em situações de AP. Uma das intervenções identificadas, estando presente em seis artigos, está relacionada ao trabalho do/a psicólogo/a através da realização de perícias e elaboração de laudos, entre eles os estudos de Souza e Barreto (2011), Sousa e Brito (2011), Luz, Gelain e Benincá (2014a), Fermann et al. (2017), Figueiredo (2017) e Montezuma et al. (2017). Nas situações em que há uma suspeita de AP, profissionais aptos deverão realizar perícias e, em relação aos profissionais da Psicologia, os que atuam na área forense são convocados para a realização de avaliações periciais auxiliando, entre outros aspectos, em sua identificação $(12.318,2010)$.

A perícia, segundo Taborda (2004), é um conjunto de procedimentos técnicos que têm por finalidade principal o esclarecimento de um fato de interesse da Justiça, devendo ter o acompanhamento de um perito para que seja possível a elaboração de um laudo que ajudará na decisão final. A Lei $n^{0} 12.318$, de 26 de agosto de 2010 descreve que:

$\S 1$ o O laudo pericial terá base em ampla avaliação psicológica ou biopsicossocial, conforme o caso, compreendendo, inclusive, entrevista pessoal com as partes, exame de documentos dos autos, histórico do relacionamento do casal e da separação, cronologia de incidentes, avaliação da personalidade dos envolvidos e exame da forma como a criança ou adolescente se manifesta acerca de eventual acusação contra genitor. § $20 \mathrm{~A}$ perícia será realizada por profissional ou equipe multidisciplinar habilitados, exigido, em qualquer caso, aptidão comprovada por histórico profissional ou acadêmico para diagnosticar atos de alienação parental. § 3o O perito ou equipe multidisciplinar designada para verificar a ocorrência de alienação parental terá prazo de 90 (noventa) dias para apresentação do laudo, prorrogável exclusivamente por autorização judicial baseada em justificativa circunstanciada.

Em seu estudo, Fermann et al. (2017), analisam oito laudos realizados por psicólogos/as, promovendo uma crítica em relação a estes, considerando a inadequação em alguns dos critérios que são essenciais, conforme Resolução do CFP 07/2003, atualmente revogada para Resolução CFP 06/2019, que descreve sobre a produção de documentos na área da Psicologia no Brasil, e nos procedimentos de avaliação adotados, os quais seguiriam inadequados pela nova legislação. Pode-se dizer que Sousa e Brito (2011) corroboram com o estudo anterior, principalmente por considerarem que, em muitas situações, o que parece ser esperado de profissionais da Psicologia é que, por meio das perícias, alguns dos aspectos observados nos sujeitos envolvidos sejam relacionados aos sintomas e comportamentos que integram a lista daqueles que seriam identificados em situações de AP ou da SAP. Em relação à elaboração de laudos periciais, as autoras destacam que o trabalho do/a psicólogo/a está aparentemente sendo confundido com as práticas de advogados(as) ou investigadores(as), em desacordo com as orientações dadas pelo Conselho Federal de Psicologia (CFP), respondendo somente a um dos lados do processo, ou não efetivando uma avaliação psicológica completa, o que deixa evidente a necessidade dos/as psicólogos/as levarem em consideração questões históricas e sociais de todos os sujeitos envolvidos nas avaliações que são realizadas, nunca esquecendo do código de ética profissional (Resolução $\left.n^{\circ} 10,2005\right)$, para a elaboração de um laudo.

Na pesquisa realizada por Luz, Gelain e Lima (2014b), destaca-se a importância do trabalho do/a psicólogo/a na área do Direito de Família. A partir de algumas das respostas que obtiveram em seu estudo, foram identificados aspectos positivos e negativos relacionados a participação da Psicologia na área jurídica. Os pontos positivos estariam relacionados com o 
fato de que o profissional poderia auxiliar na identificação de conflitos emocionais, bem como qual seria a motivação dos comportamentos de litígio, auxiliando assim na busca pela solução do caso em questão. Em contraponto, um dos pontos negativos que surgiu é de que, em muitas vezes, as intervenções dos profissionais da Psicologia acabam sendo limitadas a partir do tempo estabelecido pelo judiciário ou pelo número de sessões, ou seja, há uma grande demanda em relação aos pedidos de avaliações psicológicas. Ainda para as autoras, são criadas grandes expectativas em relação ao trabalho do/a psicólogo/a na produção de provas e na conduta das intervenções, o que pode interferir no trabalho final que será apresentado.

Podemos identificar que, no estudo de Montezuma et al. (2017), em que foram entrevistados cinco juízes, dois mediadores, seis psicólogos e dois assistentes sociais de uma equipe de estudos psicossociais que dá suporte ao juiz, um dos entrevistados valida o que foi referido por Sousa e Brito (2011), no momento em que diz ficar preocupado com o fato de que exijam das perícias realizadas por psicólogos/as um "há ou não há" AP, devendo comprovar ou não a existência de algo. Neste sentido, vale a pena destacarmos a diferença existente entre o perito e o/a psicólogo/a assistente, a partir da Resolução CFP No 008/2010. Em seu relatório, o primeiro irá apresentar indícios relacionados a sua investigação que possam auxiliar o juiz a partir da solicitação realizada, sem adentrar em pontos e decisões que cabem de forma exclusiva ao magistrado. Em relação ao/a psicólogo/a assistente, este terá sua análise restrita ao estudo psicológico consequente da perícia, elaborando questões que possam esclarecer aspectos que estejam contraditórios ou que não foram abordados.

No estudo de Souza e Barreto (2011) e Figueiredo (2017), a atuação do/a psicólogo/a a partir de perícias e laudos é citada de forma breve a partir da Lei $\mathrm{N}^{\circ} 12.318 / 10$. Um dos aspectos que poderia justificar tal questão seria o fato de que nenhum dos autores é da área da Psicologia, contudo abordam a importância da transdisciplinaridade e multidisciplinaridade nos casos de AP.

No estudo de Mendes et al. (2016), o principal objetivo foi analisar as publicações psicojurídicas sobre alienação parental entre os anos de 2008 à 2014, utilizando cinco etapas para que a revisão pudesse ser feita. Desta forma identificaram que, dos 29 artigos analisados, apenas 5 pertenciam a área da Psicologia, sendo os demais da área do Direito, o que está relacionado aos objetivos do estudo realizado. Contudo, identificamos uma diferença em tal aspecto ao longo de nossas buscas e análises já que 10 dos 13 artigos analisados têm entre seus autores ao menos um/a psicólogo/a e/ou estudante de Psicologia. Identificamos que isso está diretamente relacionado ao fato de termos buscado identificar as intervenções desses profissionais nas situações de AP, ou seja, aos objetivos de nosso estudo. Outro ponto importante a ser ressaltado é o fato de que a lei $\mathrm{n}^{\circ} 12.318$ foi promulgada no ano de 2010 o que faz com que, no presente estudo, os profissionais da psicologia tenham obtido mais conhecimento sobre o tema, consequentemente produzindo seus estudos,

Apesar da intervenção de profissionais da Psicologia relacionados à realização de perícias e laudos ter certo predomínio em situações de AP, autores como Luz et al. (2014a), Nüske e Grigorieff (2015), Fermann e Pelisoli (2016) e Figueiredo (2017) apresentam em seus estudos o acompanhamento psicológico, psicoterápico, como uma das formas de cuidado relacionadas ao trabalho do/a psicólogo/a a partir de dissoluções conjugais e disputas parentais. É interessante observarmos que, no estudo de Montezuma et al. (2017), um dos entrevistados demonstrou sua opinião referindo que, antes de ingressar com uma ação, as pessoas deveriam passar por uma psicoterapia para compreender melhor o que estaria acontecendo naquela situação familiar, antes da tomada de uma decisão judicial.

Na maior parte de seu estudo, Nüske e Grigorieff (2015) referem situações 
relacionadas ao processo de AP produzidas a partir do divórcio e acreditam que a psicoterapia pode auxiliar os genitores e especialmente a criança/adolescente na compreensão da nova dinâmica familiar existente após a separação dos pais.

Sousa (2014) aponta que, a partir de toda a situação de sofrimento, haverá a busca por uma vítima e um culpado para que este seja responsabilizado e punido pelos danos que teriam sido causados. E reforça os estudos de Sousa e Brito (2011) ao referir que o papel dos profissionais da Psicologia em situações como AP, bullying e assédio moral tem sido resumido no ato de destacar nos avaliados sintomas presentes dos manuais diagnósticos, fazendo com que assim, este seja novamente considerado vítima, tanto filhos(as) quanto progenitor(a). Contudo, as autoras consideram que as intervenções da Psicologia nos casos de AP não podem se reduzir ao diagnóstico ou produção de provas, legitimando assim uma forma de judicialização da vida.

Pode-se pensar que situações que envolvem AP, dissolução do casamento e conflitos familiares só chegam até profissionais da Psicologia que estejam trabalhando na área jurídica, entretanto, tais situações aparecem em diversos locais, entre elas no âmbito escolar e clínico. Para Jesus e Cotta (2016), o ambiente escolar tem grande importância em relação ao cuidado para com situações de AP, por exemplo, podendo aumentar ou diminuir os sintomas que atingem crianças e suas famílias.

Para Fermann e Pelisoli (2016), algumas técnicas cognitivo-comportamentais poderiam ser utilizadas para as ditas vítimas de eventos traumáticos, estando entre elas a psicoeducação, exposição imagística, exposição gradual, reestruturação cognitiva, terapia do processamento cognitivo, manejo de ansiedade e técnicas de relaxamento. Ainda para estas autoras, é importante que o/a psicólogo/a possa trabalhar com o vínculo entre a criança/adolescente e seus pais ou cuidadores, além de destacar ser importante o estabelecimento de uma boa aliança terapêutica. Dessa forma, as técnicas utilizadas em situações de Transtorno Pós-Traumático também podem ter resultados positivos em situações que envolvem AP.

Em seu estudo, Coelho e Morais (2014) contextualizam a AP a partir de considerações e termos utilizados na teoria sistêmica. Em relação às intervenções de profissionais da Psicologia, as autoras referem que é necessário compreender a família que está passando por aquela situação como um todo, visando identificar formas de intervenção mais adequadas para aquele momento.

O processo de mediação também é uma das possibilidades de intervenção de profissionais da Psicologia em situação de AP, segundo os estudos de Luz et al. (2014b), e Mendes et al. (2016). Para Montezuma et al. (2017), o processo de mediação é citado, porém, de uma forma mais geral, não há maior aprofundamento em relação aos profissionais da Psicologia. Luz et al. (2014b) apresentam o processo de mediação como uma das alternativas para diminuir e amenizar as situações conflituosas que, muitas vezes, surgem a partir de uma situação de divórcio, sendo uma dessas a SAP. Através de pesquisa num projeto de práticas jurídicas universitárias no interior do Rio Grande do Sul, identificouse que os profissionais da Psicologia foram indispensáveis durante as mediações, bem como nos encaminhamentos realizados posteriormente.

Rosa e Warpechowski (2011) sustentam que a AP é uma situação que está exigindo cada vez mais um trabalho interdisciplinar, envolvendo profissionais de diversas áreas, como psicólogos/as, advogados/as, assistentes sociais, entre outros operadores do direito, concepção também sustentada por Figueiredo (2017). Segundo Souza e Barreto (2011), temáticas relacionadas ao Direito de Família, estando entre elas a AP, passam a demandar um trabalho transdisciplinar, principalmente relacionando saberes da Psicologia e do Direito. No estudo de Montezuma et al. (2017), a atuação de equipes multiprofissionais também é citada por parte de um dos 
entrevistados, na realização de perícias psicológicas ou biopsicossociais.

\section{Considerações finais}

A partir do presente estudo, pode-se identificar que o trabalho do/a psicólogo/a em situações de AP ainda está muito atrelado à identificação da presença ou ausência da mesma, fazendo com que não sejam propostas formas de promoção do cuidado de crianças, adolescentes e para todos os sujeitos envolvidos. Conclui-se que, apesar do grande aumento pela busca de especialização a partir do decreto da Lei $\mathrm{n}^{\mathrm{o}} 12.318 / 10$, muitos dos profissionais da Psicologia ainda necessitam melhorar sua qualificação para a elaboração de laudos e realização de perícias, seguindo a Resolução 06/2019 e o código de ética profissional.

A principal contribuição desde estudo consta como consideração que a alienação parental nem sempre provoca distúrbios somente na criança ou adolescente alienados, mas esse fenômeno precisa ser compreendido dentro de cada sistema familiar, por isso, a utilização do termo Síndrome de Alienação Parental pode limitar a sua compreensão e patologizar uma das partes da família. Inclusive a síndrome precisa de mais estudos em relação aos sintomas para o fechamento de um diagnóstico em si. Os artigos analisados indicam que as intervenções da Psicologia em situações de AP acabam sendo banalizadas, focalizando unicamente no diagnóstico e na judicialização das vidas, ou seja, uma forma de intervenção incompleta e ineficiente para as famílias que precisam reatar seus laços ou reconstruí-los. Há uma busca pelo diagnóstico por solicitação da justiça, que deveria repercutir na ressignificação dos vínculos de todos os sujeitos que estão envolvidos na situação. Contudo, a questão diagnóstica acaba sendo resumida em uma busca por comprovar a presença ou ausência de AP, muitas vezes não avaliando as consequências posteriores.

Apesar dos artigos analisados abordarem questões relacionadas a interdisciplinaridade, transdisciplinaridade e equipes multiprofissionais, é necessário pensarmos se tais práticas realmente ocorrem, ou se há uma busca de intervenções fragmentadas onde cada profissional irá procurar sanar os ditos sintomas através dos saberes que domina na sua área, sem buscar outras formas de proteção para cada sujeito. Além disso, é necessário pensarmos sobre a singularidade de cada sujeito, cada família, considerando que cada situação deverá ser vista a partir da ampliação da análise, levando sempre em consideração suas vivências e contexto social.

Por fim, concluímos que a AP pode ser considerada uma temática recente no Brasil, o que demonstra que ainda há necessidade de realização de pesquisas empíricas sobre o tema, principalmente, relacionando este com o trabalho de profissionais da Psicologia e operadores do Direito para garantir os direitos às crianças e aos adolescentes ao convívio saudável dentro das diferentes possibilidades e formatos de famílias.

\section{Referências}

Abranches, C. D., \& Assis, S. G. (2011). A

(in)visibilidade da violência psicológica na

infância e adolescência no contexto

familiar. Cadernos de Saúde Pública,

27(5), 843-854. doi: 10.1590/S0102-

311X2011000500003
Bee, H., \& Boyd, D. (2011). A criança em desenvolvimento (12a ed.). Porto Alegre: Artmed.

Campos, R. (2002). Separação conjugal e a criança. Rio de Janeiro. Recuperado de http://www.avm.edu.br/monopdf/3/ROSAN E\%20CAMPOS.pdf 
Coelho, D. M. (2017). Conjugalidade: aliança, crise e ressignificação. Porto Alegre: Mikelis Ed.

Coelho, M. I. S. M., \& Morais, N. A., (2014). Contribuições da Teoria Sistêmica acerca da Alienação Parental. Contextos Clínicos, 7(2), 168-181. doi:

10.4013/ctc.2014.72.05

De Antoni, C. (2012). Abuso emocional parental contra crianças e adolescentes. In L. F. Habigzang \& S. H. Koller (Orgs.), Violência contra crianças e adolescentes: Teoria, Pesquisa e Prática (pp. 33-32). Porto Alegre: Artmed.

Féres-Carneiro, T. (2008). Alienação Parental: Uma leitura psicológica. In A, R. Paulino (Org), Síndrome da Alienação Parental e a tirania do guardião: aspectos psicológicos, sociais e jurídicos. Porto Alegre:

Equilíbrio.

Fermann, I. L., Chambart, D. I., Foschiera, L. N., Bordini, T. C. P. M.., \& Habigzang, L. F. (2017). Perícias psicológicas em processos judiciais envolvendo suspeita de alienação parental. Psicologia: Ciência e Profissão, 37(1), 35-47. Recuperado de http://www.scielo.br/pdf/pcp/v37n1/19823703-pcp-37-1-0035.pdf

Fermann, I. L., \& Pelisoli, C. L. (2016). A Psicoterapia Cognitivo - Comportamental para Crianças e Adolescentes vítimas de Violência Psicológica e Alienação Parental. Revista de Psicologia da IMED, 8(1), 7686. doi: 10.18256/2175-5027/psicoimed.v8n1p76-86

Figueiredo, C. R. L. V., (2017). A ira dos anjos: uma análise psicológica e jurídica da alienação parental. JURIS - Revista da Faculdade de Direito, 27(2), 119-138. doi: 10.14295/juris.v27i2.7098

Gardner, R. (2002). O DSM-IV tem equivalente para o diagnóstico de Síndrome de Alienação Parental (SAP)? Recuperado de https://bit.ly/2MsldjJ

Galvão, T. F., \& Pereira, M. G. Revisões sistemáticas da literatura: passos para sua elaboração. Epidemiologia e Serviços de Saúde, 23(1), 183-184. Recuperado de http://scielo.iec.gov.br/scielo.php?script=sci arttext\&pid $=$ S167949742014000100018\&lng $=p t \& t \operatorname{lng}=p t$ Guanilo, M. C. D. T. U., Takahashi, R. F., \& Bertolozzi, M. R., (2011). Revisão sistemática: noções gerais. São Paulo: Revista da Escola de Enfermagem da USP, 45(5), 1260-1266. Recuperado de http://www.scielo.br/pdf/reeusp/v45n5/v45 n5a33.pdf

Guilhermano, J. F. (2012). Alienação Parental: Aspectos Jurídicos e Psíquicos (Trabalho de Conclusão de Curso). Escola de Direito e Relações Internacionais, Pontifícia Universidade Católica de Goiás, GO, Brasil. Recuperado de https://repositorio.pucgoias.edu.br/jspui/han dle/123456789/1964

Jesus, J. A., \& Cotta, M. G. L., (2016). Alienação parental e relações escolares: a atuação do psicólogo. Psicologia Escolar e Educacional, 20(2), 285-290. Recuperado de

http://www.scielo.br/pdf/pee/v20n2/21753539-pee-20-02-00285.pdf

Kell, M. R., (2004). Ressentiment. São Paulo: Casa do Psicólogo.

Lei $\mathrm{n}^{\circ} 12.318$, de 26 de agosto de 2010.

Dispõe sobre a alienação parental e altera o art. 236 da Lei no 8.069, de 13 de julho de 1990. Recuperado de http://www.planalto.gov.br/ccivil 03/ ato2 007-2010/2010/1ei/112318.htm

Luz, A. F., Gelain, D., \& Benincá, T. K., (2014a). A Atuação do Psicólogo Jurídico na Alienação Parental. Revista de Psicologia da IMED, 6(2), 81-88. doi: https://doi.org/10.18256/2175-5027/psicoimed.v6n2p81-88

Luz, A. F., Gelain, D., \& Lima, L. R. (2014b). Reflexões sobre alienação parental em um projeto de mediação de conflitos. Revista Psicologia e Saúde, 6(2), 96-103.

Recuperado de http://pepsic.bvsalud.org/pdf/rpsaude/v6n2/ v6n2a12.pdf

Melo, N. S., \& Miccione, M. M. (2014). As Consequências do Divórcio dos pais sobre o desenvolvimento infantil: contribuição da abordagem cognitivo-comportamental. Revista Estação Científica, 12, 1-20. 
Recuperado de

http://portal.estacio.br/docs $\% 5$ Crevista est acao cientifica/03.pdf

Mendes, J. A. A., Maluschke, J. S. N. F. B., Vasconcelos, D. F., Fernandes, G. A., \& Costa, P. V. M. N., (2016). Publicações psicojurídicas sobre alienação parental: uma revisão integrativa de literatura em português. Psicologia em Estudo, 21(1), 161-174. doi:

10.4025/psicolestud.v21i1.29704

Montezuma, M. A., Pereira R. C., \& Melo, E. M., (2017). Abordagens da alienação parental: proteção e/ou violência?. Revista de Saúde Coletiva, 27(4), 1205-1224. doi: 10.1590/S0103-73312017000400018

Morais, M. C., (2012). Alienação parental: aportes conceituais, aspectos jurídicos e meios de prova. Ambito Jurídico, 106.

Recuperado de

https://ambitojuridico.com.br/edicoes/revist a-106/alienacao-parental-aportes-

conceituais-aspectos-juridicos-e-meios-deprova/

Neder, G., \& Filho, G. C. (2007). Ideias jurídicas e autoridade na família. Rio de Janeiro: Reven Ed.

Nüske, J. P. F., Grigorieff, A. G., (2015). Alienação parental: complexidades despertadas no âmbito familiar. Pensando familias, 19(1), 77-87. Recuperado de http://pepsic.bvsalud.org/scielo.php?script= sci arttext\&pid $=$ S1679494X2015000100007\&lng=pt\&tlng=pt

Oliveira, C. F. B., \& Brito, L. M. T. (2013). Judicialização da vida na contemporaneidade. Psicologia: Ciência e Profissão, 33, 78-89. Recuperado de http://www.scielo.br/scielo.php?script=sci arttext\&pid $=$ S141498932013000500009\&lng=en\&tlng=pt

Organização Mundial de Saúde [OMS]. (2002). Relatório Mundial de Violência e Saúde. Genebra: OMS. Recuperado de https://www.opas.org.br/wpcontent/uploads/2015/09/relatorio-mundialviolencia-saude.pdf

Papalia, D. E., Olds, Sally W., \& Feldman, R. D. (2006). Desenvolvimento humano (8a ed). Porto Alegre: Artmed.
Pasqua, L. D. (2017). Parentalidade: Educação Compartilhada. Porto Alegre: Mikelis Ed.

Prado Filho, K., (2012). Uma breve genealogia das práticas jurídicas no ocidente. Psicologia \& Sociedade, 24(spe), 104-111. doi: 10.1590/S010271822012000400015

Resolução $\mathrm{n}^{\circ}$ 6, de 29 de março de 2019. Institui regras para a elaboração de documentos escritos produzidos pela(o) psicóloga(o) no exercício profissional e revoga a Resolução CFP n ${ }^{\circ} 15 / 1996$, a Resolução CFP no 07/2003 e a Resolução CFP no 04/2019. Recuperado de https://www.in.gov.br/materia//asset publisher/Kujrw0TZC2Mb/content/i d/69440957/do1-2019-04-01-resolucao-n6-de-29-de-marco-de-2019-69440920

Resolução CFP n. ${ }^{\circ}$ 010/2005, de 21 de julho de 2005. Aprova o Código de Ética Profissional do Psicólogo. Recuperado de https://site.cfp.org.br/wpcontent/uploads/2005/07/resolucao2005 10 . $\mathrm{pdf}$

Resolução CFP n. ${ }^{\circ}$ 007/2003, de 14 de junho de 2003. Institui o Manual de Elaboração de Documentos Escritos produzidos pelo psicólogo, decorrentes de avaliação psicológica e revoga a Resolução $\mathrm{CFP}^{\circ}$ 17/2002. Recuperado de https://site.cfp.org.br/wpcontent/uploads/2003/06/resolucao2003 7. pdf

Resolução CFP n ${ }^{0}$ 008/2010, de 30 de junho de 2010. Dispõe sobre a atuação do psicólogo como perito e assistente técnico no Poder Judiciário. Recuperado de https://site.cfp.org.br/wpcontent/uploads/2010/07/resolucao2010 00 $\underline{\text { 8.pdf }}$

Rosa, C. P., Warpechowski, A., (2011). Direito e Psicologia: O desafio da interdisciplinaridade. Porto Alegre: UniRitter.

Simão, R. B. C., (2008). Soluções judiciais concretas contra a perniciosa prática da Alienação Parental. In A, R. Paulino (Org), Síndrome da Alienação Parental e a tirania 
do guardião: aspectos psicológicos, sociais e jurídicos. Porto Alegre: Equilíbrio.

Sousa, A. M., \& Brito, L. M. T. (2011).

Síndrome de Alienação Parental: da Teoria Norte - Americana à Nova Lei Brasileira. Psicologia: Ciência e Profissão, 31(2), 268-283. Recuperado de http://www.scielo.br/pdf/pcp/v31n2/v31n2a 06.pdf

Sousa, A. M. (2014). A consagração das vítimas nas sociedades de segurança. Revista EPOS, 5(1), 29-56. Recuperado de http://revistaepos.org/arquivos/09/Analicia Sousa 09.pdf
Souza, A. M. O., \& Barreto, R. M., (2011). Síndrome de alienação parental, falso abuso sexual e guarda compartilhada: a necessidade de uma observação jurídica transdisciplinar. Espaço Jurídico, 12(1), 67-82. Recuperado de https://portalperiodicos.unoesc.edu.br/espac ojuridico/article/view/1400.

Taborda, J. G. V., (2004). Exame Pericial Psiquiátrico. In J. V. Taborda, M. Chalub, \& E. A. Filho (Orgs.), Psiquiatria Forense (pp. 43-67). Porto Alegre: Artmed.

Velly, A. M. F. (2010). A Síndrome da Alienação Parental: uma Visão Jurídica e Psicológica. Forense: São Paulo.

\section{Dados sobre as autoras:}

- Suany Chisté Benvegnú: Graduada de Psicologia da Universidade do Vale do Taquari Univates.

- Priscila Pavan Detoni: Psicóloga, Mestre e Doutora em Psicologia Social e Institucional pela Universidade Federal do Rio Grande do Sul (UFRGS); Membro do Núcleo de Pesquisa em Relações de Gênero e Sexualidade (Nupsex/UFRGS) e do Centro de Referência em Direitos Humanos: Relações de Gênero, Diversidade Sexual e de Raça (CRDH/UFRGS); docente no Centro Universitário do Vale do Taquari de Ensino Superior (UNIVATES). Possuí estudos e trabalha com ênfase nas temáticas da psicologia social, políticas sociais públicas, direitos humanos, saúde do/a trabalhador/a, estudos feministas, relações de gênero e sexualidade.

- Olinda Maria de Fátima Lechmann Saldanha: Graduação em Psicologia, Bacharelado e Licenciatura pela Universidade de Passo Fundo (1982), Especialização em Ativação de Mudanças na Formação Superior de Saúde; Especialização em Metodologia do Ensino e da Pesquisa; Especialização em Saúde Mental Coletiva. Mestrado em Psicologia Social e Institucional pela Universidade Federal do Rio Grande do Sul (2004) e Doutorado em Educação pela UFRGS (2013). Foi Professora Adjunta da Universidade do Vale do Taquari - Univates, atuando como representante dos docentes no Conselho de Centro e no Conselho Universitário. Atualmente, professora no Departamento de Psicologia da Universidade de Santa Cruz do Sul. Tem experiência na área de Psicologia, com ênfase em Psicologia Social. Trabalha e pesquisa na área da Saúde Coletiva, com ênfase em Sistemas e Políticas de Saúde principalmente nos seguintes temas: saúde coletiva, saúde mental, gestão autônoma da Medicação (GAM), políticas públicas, educação e saúde, gestão em saúde. direitos autorais para os artigos publicados são do autor, com direitos do periódico sobre a primeira publicação. Os autores somente poderão utilizar os mesmos resultados em outras publicações indicando claramente este periódico como o meio da publicação original. Em virtude de sermos um periódico de acesso aberto, permite-se o uso gratuito dos artigos em aplicações educacionais e científicas desde que citada a fonte conforme a licença CC-BY da Creative Commons. 